\title{
Dietary Compound Resveratrol Is a Pan-BET Bromodomain Inhibitor
}

\author{
Luiz Antonio Dutra 1,2, David Heidenreich ${ }^{2}$, Gabriel Dalio Bernardes da Silva ${ }^{1}$, \\ Chung Man Chin 1,* (D), Stefan Knapp ${ }^{2}$ and Jean Leandro dos Santos ${ }^{1, *}$ \\ 1 School of Pharmaceutical Sciences, São Paulo State University (UNESP), Araraquara 14800903, Brazil; \\ luizdutra_qf@yahoo.com.br (L.A.D.); gabriel.dalio@hotmail.com (G.D.B.d.S.) \\ 2 Institute for Pharmaceutical Chemistry and Buchmann Institute for Life Sciences, Goethe-University, \\ D-60438 Frankfurt am Main, Germany; heidenreich@pharmchem.uni-frankfurt.de (D.H); \\ Knapp@sgc.ox.ac.uk (S.K) \\ * Correspondence: santosjl@fcfar.unesp.br (J.L.d.S.); chungmc@fcfar.unesp.br (C.M.C.); \\ Tel.: +55-16-3301-6972 (J.L.d.S.)
}

Received: 14 August 2017; Accepted: 20 October 2017; Published: 27 October 2017

\begin{abstract}
The chemopreventive and anticancer effects of resveratrol (RSV) are widely reported in the literature. Specifically, mechanisms involving epigenetic regulation are promising targets to regulate tumor development. Bromodomains act as epigenetic readers by recognizing lysine acetylation on histone tails and boosting gene expression in order to regulate tissue-specific transcription. In this work, we showed that RSV is a pan-BET inhibitor. Using Differential Scanning Fluorimetry (DSF), we showed that RSV at $100 \mu \mathrm{M}$ increased the melting temperature $(\Delta \mathrm{Tm})$ of BET bromodomains by around $2.0^{\circ} \mathrm{C}$. The micromolar dissociation constant $\left(K_{\mathrm{d}}\right)$ range was characterized using Isothermal Titration Calorimetry (ITC). The RSV $K_{\mathrm{d}}$ value accounted to $6.6 \mu \mathrm{M}$ in case of BRD4(1). Molecular docking proposed the binding mode of RSV against BRD4(1) mimicking the acetyl-lysine interactions. All these results suggest that RSV can also recognize epigenetic readers domains by interacting with BET bromodomains.
\end{abstract}

Keywords: resveratrol; bromodomains; epigenetic; Differential Scanning Calorimetry (DSF); Isothermal Titration Calorimetry (ITC)

\section{Introduction}

Resveratrol (3,5,4'-tryhydroxy-stilbene) is a naturally occurring polyphenol found in apples, peanuts, plums, berries, and fruit seeds of Vitis venifera species. This compound has received worldwide attention due to its role in regulating multiple transduction pathways of several diseases, including cancer, cardiovascular, neurodegerative, and inflammatory diseases [1].

For cancer, RSV interferes in the different stages of tumors development, such as initiation, promotion, and progression [2]. The role of this compound on angiogenesis and metastasis is also described in the literature [3,4]. Both intrinsic and extrinsic apoptotic pathways are involved in apoptosis induced by RSV [5]. It has been described that the anticancer and chemopreventive effects of RSV are associated with activation/upregulation of the mitogen-activated protein kinase (MAPK) and sirtuins (SIRT). Moreover, inhibition and/or downregulation of the following targets/pathways are described for RSV: the phosphatidylinositol 3-Kinase (PI3K) pathway, cyclin-dependent kinase 4 and 6 (CDK4 and CDK6), cyclins D1 and D3, and the signal transducer and activator of transcription 3 (STAT-3), p21 and p53 [6].

Among the multiple effects of RSV against cancer, those involving the regulation of epigenetic mechanisms seem to be promising to regulate tumor development [7]. RSV is able to activate sirtuin-1 (SIRT-1), a class III of histone deacetylase (HDAC), leading to transcriptor factors deacetylation and cell 
proliferation inhibition [8]. In addition, this compound is a pan-HDACs inhibitor acting against eleven different HDACs of class I, II, and IV in a dose-dependent manner [9]. Despite these well-established effects, RSV activity against other epigenetic targets such as bromodomains is still unknown.

Bromodomains (BRDs) are epigenetics "readers" because they recognize lysine acetylation in histone tails and other nuclear proteins to boost gene expression, which has been involved in the development of many diseases, including cancer. Currently, 61 bromodomains present in 46 proteins have been reported [10]. Crystallographic data revealed the binding mode of acetyl-lysine (KAc) to bromodomains, showing that the acetyl group binds to the central hydrophobic pocket of BRDs, anchored by asparagine 140 residue (Asn140) and mediated by water molecules [10]. Bromo and Extra Terminal domains (BET)-BRDs comprise four members in humans (i.e. BRD2, BRD3, BRD4, and BRDT), whose dysfunction has been associated with the development of NUT midline carcinoma [10,11]. BRD4(1) has received attention after the discovery of the potent and selective pan-BET inhibitor (JQ1), which exhibited outstanding antiproliferative activity against the BRD4(1)-dependent cell line [11]. A different compound, RVX208, which is structurally related to RSV, is a bromodomain inhibitor that recognizes the second bromodomain in BETs. For this molecule, high selectivity (superior to 20) was characterized for BD2 of BRD2 and BRD3 [12].

In order to evaluate the ability of the dietary compound RSV to inhibit BET-BRDs, we performed here the screening against BRD2, BRD3, BRD4, and BRDT using Differential Scanning Fluorimetry (DSF). Isothermal Titration Calorimetry (ITC) was used to determine the binding constant $\left(K_{\mathrm{d}}\right)$ for BRD4. Moreover, the binding mode of RSV into Kac of BRD4(1) was proposed using molecular docking.

\section{Material and Methods}

\subsection{Protein Expression}

\subsubsection{Low Scale Expression}

Plasmid vectors coding bromodomains (BRD2(1), BRD3(1), BRD4(1), BRDT(1) and BRD4(2)) were added into Eppendorf tube (Greiner Bio One, Kremsmünster, Austria) containing chemically competent E. coli BL21 (DE3) cells, which were kept on ice for $30 \mathrm{~min}$. For this solution, heat shock was performed at $42{ }^{\circ} \mathrm{C}$ for $40 \mathrm{~s}$, and then it was kept in on ice. Luria-Bertani (LB) Broth (Carl Roth, Karlsruhe, Germany) medium was added $(100 \mu \mathrm{L})$ and all cells were grown at $37^{\circ} \mathrm{C}$ for $1 \mathrm{~h}$. After, cells were selected on plates enriched by agar containing kanamycin $(50 \mu \mathrm{g} / \mathrm{mL}$ ) (Carl Roth, Karlsruhe, Germany) and chloramphenicol $(34 \mu \mathrm{g} / \mathrm{mL}$ ) (Amresco, Solon, ME, USA). Then, $50 \mathrm{~mL}$ of $2 \times \mathrm{LB}$ medium concentration with kanamycin $(50 \mu \mathrm{g} / \mathrm{mL}$ ) (Carl Roth, Karlsruhe, Germany) and chloramphenicol $(34 \mu \mathrm{g} / \mathrm{mL})$ (Amresco, Solon, ME, USA) were inoculated with the selected cells. The cells were grown overnight $\left(200 \mathrm{RPM}, 37^{\circ} \mathrm{C}\right)$.

\subsubsection{Large Scale Expression}

Terrific broth medium (TB medium) was prepared in advance $(4 \times$ concentrated and autoclaved). This medium was diluted in water $(1 \mathrm{~L})$ and the medium containing the cells and kanamycin $(50 \mu \mathrm{g} / \mathrm{mL})$ (Carl Roth, Karlsruhe, Germany) was pipetted at a volume of $10 \mathrm{~mL}$. The cells were grown up to 1.5 of Density Optical (DO) $\left(200 \mathrm{RPM}, 37^{\circ} \mathrm{C}\right)$. The shaker was set up at $18^{\circ} \mathrm{C}$, and the cells were grown up to $3.0 \mathrm{DO}(180 \mathrm{RPM})$ and then induced overnight with $500 \mu \mathrm{M}$ of Isopropyl $\beta$-D-1-thiogalactopyranoside (IPTG) (Amresco, Solon, ME, USA). After, the cells were harvested at $8.700 \mathrm{~g}$ using centrifuge Sorval LyNX 6000-Thermo (Thermo Fisher Scientific, Waltham, MA, USA) and stored at $-20^{\circ} \mathrm{C}$. 


\subsection{Protein Purification}

\subsubsection{Affinity Chromatography with $\mathrm{Co}^{2+}$ Beads}

The harvested cells were resuspended in $30 \mathrm{~mL}$ lysis buffer (50 mM HEPES pH 7.4, $500 \mathrm{mM} \mathrm{NaCl}$, $1 \mathrm{mM}$ TCEP, $15 \mathrm{mM}$ imidazole, and 5\% glycerol) and lysed using a cell sonicator (35\% amplitude, cycling $5 \mathrm{~s}$ 'on', and $10 \mathrm{~s}$ 'off' for $3 \mathrm{~min}$ ). After that, $0.15 \%$ of Polyethyleneimine (PEI) (Fluka (Honeywell), Morris Plains, NJ, USA) were added and the cell debris was centrifuged (23.000 RPM, $\left.30 \mathrm{~min}, 4{ }^{\circ} \mathrm{C}\right) . \mathrm{Co}^{2+}$ beads $(5 \mathrm{~mL})$ were added to a glass column $(3 \mathrm{~cm}$ diameter $)$, washed with water $(50 \mathrm{~mL})$ and followed by equilibration using lysis buffer $(50 \mathrm{~mL})$. The cellular lysate containing protein was eluted through stationary phase chromatography using imidazole in lysis buffer $(30 \mathrm{mM}, 50 \mathrm{mM}$, $100 \mathrm{mM}$, and $2 \times 300 \mathrm{mM}$ ). This procedure was performed at $4{ }^{\circ} \mathrm{C}$ and purity fractions were analyzed by SDS-PAGE [13]. The fractions were concentrated by centrifugal filters (Merck Millipore, Burlington, VT, USA) and stored at $4{ }^{\circ} \mathrm{C}$.

\subsubsection{Rebinding with $\mathrm{Ni}^{2+}$ Beads}

Protein fractions were gathered from $\mathrm{Co}^{2+}$ beads column followed by His-tag cleavage using TEV ( $20 \times$ less TEV concentration than protein concentration) in $20 \mathrm{~mL}$ TEV buffer ( $30 \mathrm{mM}$ HEPES, $300 \mathrm{mM} \mathrm{NaCl}, 0.5 \mathrm{mM}$ TCEP, $5 \%$ glycerol) at $4{ }^{\circ} \mathrm{C}$ overnight. That protein solution was applied to a column containing $2 \mathrm{~mL}$ of $\mathrm{Ni}^{2+}$ beads. The stationary phase chromatography was equilibrated with TEV buffer $(12 \mathrm{~mL})$, and then the sample was eluted and collected completely followed by two more elutions (12 mL each) using $30 \mathrm{mM}$ and $300 \mathrm{mM}$ imidazole in TEV buffer, respectively. All procedures were performed at $4{ }^{\circ} \mathrm{C}$. Those samples were analyzed by SDS-PAGE and concentrated through centrifugal filter (Merck Millipore, Burlington, VT, USA) up to $20 \mathrm{mg} / \mathrm{mL}$ and stored at $4{ }^{\circ} \mathrm{C}$.

\subsubsection{Size Exclusion Chromatography (SEC)}

The chromatography column Superdex 75 Increase (GE HealthCare, Little Chalfont, UK) was equilibrated beforehand using gel filtration buffer (10 mM HEPES, $150 \mathrm{mM} \mathrm{NaCl}, 0.5 \mathrm{mM}$ TECP, and $5 \%$ glycerol) at flow of $1 \mathrm{~mL} / \mathrm{min}$. Samples were loaded through loop of $5 \mathrm{~mL}$ using that column previously which was connected to chromatograph ÄktPrime ${ }^{\mathrm{TM}}$ plus (GE HealthCare, Little Chalfont, UK) using gel filtration buffer as mobile phase. All proteins were collected in a range volume of $75-80 \mathrm{~mL}$, analyzed by SDS-PAGE, concentrated up to $10 \mathrm{mg} / \mathrm{mL}$, and then stored at $-80^{\circ} \mathrm{C}$.

\subsection{Differential Scanning Fluorimetry (DSF)}

All bromodomains were prepared at $2 \mu \mathrm{M}$ of final concentration in $2 \mathrm{~mL}$ of DSF-assay buffer (10 mM HEPES pH 7.5 and $500 \mathrm{mM} \mathrm{NaCl}$ ). Sypro Orange dye (Thermo Fisher Scientific, Waltham, MA, USA) $(2 \mu \mathrm{L})$, used as fluorescence probe, was added into the sample protein, and then the samples were pipetted $(20 \mu \mathrm{L})$ into 96 -well microplates. All compounds were diluted beforehand $(500 \mu \mathrm{M})$ in dimethyl sulfoxide (DMSO) (Carl Roth, Karlsruhe, Germany) and stored into 96-well plates at $-20^{\circ} \mathrm{C}$. RSV was pipetted into protein samples (at $10 \mu \mathrm{M}$ and $100 \mu \mathrm{M}$ of final concentration) and plate sealed with PCR seal. $\Delta T_{m}$ data for each compound was performed by qPCR machine (Agilent, Santa Clara, CA, USA), which had temperature raises of $3{ }^{\circ} \mathrm{C}$ per min in 71 cycles, 1 degree step, $21 \mathrm{~s}$, with a starting temperature of $25^{\circ} \mathrm{C}$ [11].

\subsection{Isothermal Titration Calorimetry (ITC)}

Experiments were carried out on a Nano ITC microcalorimeter (TA Instruments, New Castle, PA, USA). The experiment was carried out at $15^{\circ} \mathrm{C}$ and stirring at $350 \mathrm{RPM}$ in ITC buffer $(10 \mathrm{mM}$ HEPES pH 7.4, $150 \mathrm{mM} \mathrm{NaCl}$, and $0.5 \mathrm{mM}$ TCEP). BRD4(1) was loaded using a microsyringe $(250 \mu \mathrm{L})$ in ITC buffer. Initial titrations had injection of $4.0 \mu \mathrm{L}$ followed by 21 injections of $8 \mu \mathrm{L}$ spacing among them at $200 \mathrm{~s}$ between injections. The collected data was processed through NanoAnalyze ${ }^{\mathrm{TM}}$ 
software (Version 3.5.0, TA Instruments, New Castle, PA, USA) supplied with the instrument to yield enthalpies of binding $(\Delta H)$ and dissociation constants $\left(K_{\mathrm{d}}\right)$. Thermodynamic parameters were calculated $\left(\Delta G=\Delta H-\mathrm{T} \Delta \mathrm{S}=-\mathrm{R} T \ln \mathrm{K}_{\mathrm{B}}\right.$, where $\Delta G, \Delta H$ and $\Delta S$ are the changes in free energy, enthalpy, and entropy of binding respectively). In all experiments BRD4(1) was titrated into RSV solution (reverse titration) [11].

\subsection{Molecular Docking}

Molecular modeling studies were performed with Maestro v9.1 Software (Schrödinger Inc., New York, NY, USA) [12].The crystal structure of BRD4(1) (PDB code: 3MXF) complexed with inhibitor JQ-1 was imported from Protein Data Bank (PDB) to Schrödinger Maestro suite 2016 [14] applying OPLS3 (Optimized Potential for Liquid Simulations) force field. The crystallographic and conserved water molecules in the active site were not deleted. Hydrogen atoms were added, and formal charges, along with bond orders, were assigned to the structure. RSV was prepared for docking using LigPrep (version 11, Schröndinger, New York, NY, USA). This procedure aimed to optimize the ligand geometry, to generate low energy 3D structure, and to eliminate structural mistakes in ligands using the OPLS3 force field. The ionization states of ligands was studied at $\mathrm{pH} 7.0 \pm 2.0$ using Epik (version 11, Schröndinger, New York, NY, USA) [15]. The grid was generated as a cubic box of $10 \AA \times 10 \AA \times 10 \AA$ centered on the active site residues. The Standard Precision (SP) and Extra Precision (XP) flexible ligand docking were performed using Glide within Schrödinger-Maestro v9.1 [14]. The final score was obtained for energy-minimized poses and the best-docked pose with lowest glide score was selected for RSV. Docking protocol was validated by re-docking the ligand JQ-1 to protein, thereby aiming to verify the software capability of reproducing the same pose of the ligand observed in the crystal structure. The quality of this result was analyzed by Root-mean-square deviation (RMSD) between pose of original crystal structure and re-docked ligand. Distances up to $2 \AA$ were considered reliable to this docking protocol [15].

\section{Results}

\subsection{Differential Scanning Fluorimetry (DSF) and Isothermal Titration Calorimetry (ITC) of RSV against Bromodomains}

We have employed thermal stability assay using DSF method to evaluate the ability of RSV (at $100 \mu \mathrm{M}$ ) to interact with several BRDs of the BET family, comprising the first and second bromodomains (BD1 and BD2). In the presence of RSV, the melting temperature shifts $\left(\Delta \mathrm{T}_{\mathrm{m}}\right)$ of BRDs increased at values of $2.0^{\circ} \mathrm{C}(\mathrm{BRD} 4(1)), 2.9^{\circ} \mathrm{C}(\mathrm{BRD} 2(1)), 1.8^{\circ} \mathrm{C}(\mathrm{BRD} 3(1)), 1.5^{\circ} \mathrm{C}(\mathrm{BRDT}(1))$, and $3.0^{\circ} \mathrm{C}$ for BRD4(2), respectively (Table 1). These results revealed that RSV interacts with all of those BD1 BD2 bromodomains.

Table 1. Thermal stability data for bromodomains in the presence of resveratrol (RSV).

\begin{tabular}{cc}
\hline \multirow{2}{*}{ Protein } & Resveratrol $\mathbf{1 0 0} \boldsymbol{\mu M}$ \\
\cline { 2 - 2 } & $\boldsymbol{\Delta} \mathbf{T}_{\mathbf{m}}\left({ }^{\circ} \mathbf{C}\right)$ \\
\hline BRD2(1) & $2.0 \pm 0.5$ \\
BRD3(1) & $1.8 \pm 0.2$ \\
BRD4(1) & $2.0 \pm 0.6$ \\
BRDT(1) & $1.5 \pm 0.3$ \\
BRD4(2) & $3.0 \pm 0.5$ \\
\hline
\end{tabular}

BRD: Bromodomain; BRDT: Bromodomain Testis-Specific Protein.

Orthogonal assay using ITC was performed in order to confirm the data observed for DSF studies. For this assay, BRD4(1) was used due to its well established involvement in cancer development [16]. The obtained dissociation constant $\left(K_{d}\right)$ using ITC has demonstrated $K_{d}$ value of $6.6 \mu$ M for RSV 
against BRD4(1) (Figure 1). The affinity of RSV for BRD4(1) was due to large negative binding enthalpy $(\Delta H)$ values, suggesting favorable polar interaction with this ligand. It was found that $\Delta H$ had values of $-4.5 \mathrm{Kcal} / \mathrm{mol}$. On the other hand, RSV appears to be revealing hydrophobic interaction not favorable due to entropic change $\Delta S>0$. It was found, for RSV, that $\Delta G$ values of $-6.80 \mathrm{Kcal} / \mathrm{mol}$ were against BRD4(1).
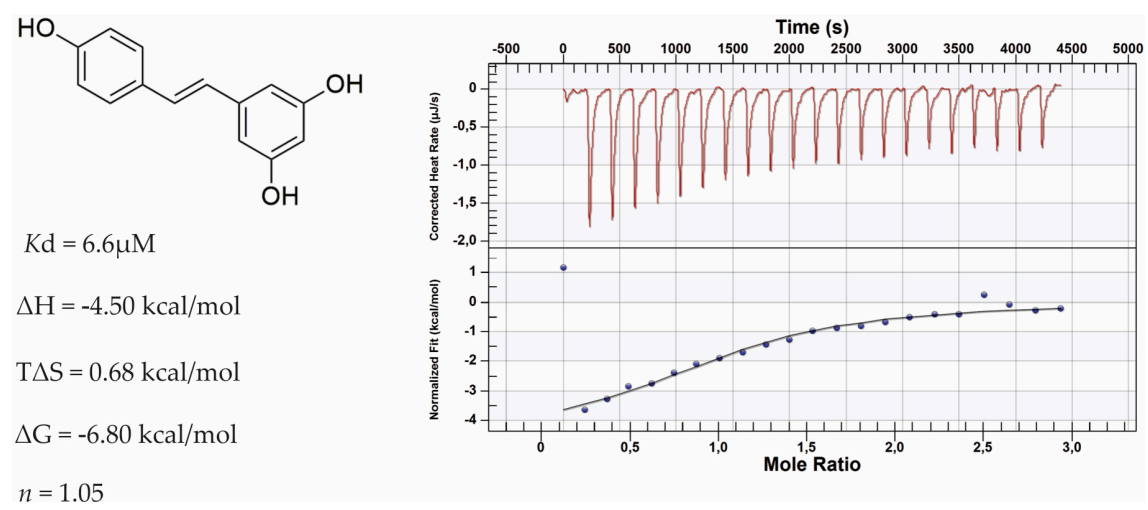

Figure 1. Isothermal Titatrion Calorimetry (ITC) data for RSV. Reverse titration of BRD4(1) into RSV buffered, BRD4(1): $400 \mu \mathrm{M}, \mathrm{RSV}: 17 \mu \mathrm{M}$.

\subsection{Binding Mode of RSV into Kac Binding Site of Bromodomains}

The possible binding mode of RSV against BRD4(1) and its interaction with the conserved Kac binding site of this bromodomain were characterized through docking studies. The result suggests that RSV occupies the Kac binding site with interactions mimicking hydrogens bond of acetyl-lysine [11]. In this case, interactions of RSV are limited to the 3,5-disubstituted ring, whose hydroxyl groups interact through hydrogens bond with Asn140 residue in the BC-loop. Unlike others inhibitors and acetyl-lysine crystal structures, RSV does not make a water-mediated hydrogen bond with Asn140 into Kac binding site (Figure 2A) [17]. On the other hand, the mono-substituted ring is oriented toward to the opened ZA-loop pocket, revealing polar interaction with Asn145 in $\alpha \mathrm{C}$ region (Figure 2B). In agreement with ITC data measurement, the molecular docking shows limited polar interactions for RSV besides lacking hydrophobic interactions, which is confirmed with $\Delta S>0$ value. Hits optimization aiming to catch up hydrophobic interactions, such as $\pi$-stacking with Trp81 into ZA-loop region, appears to provide affinity for BRD4(1) inhibitors [18,19]. The validation of docking model showed a RMSD value of $0.65 \AA$.

A

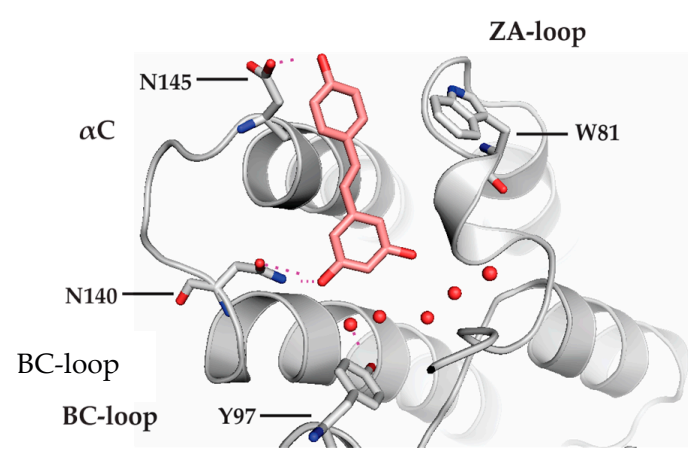

B

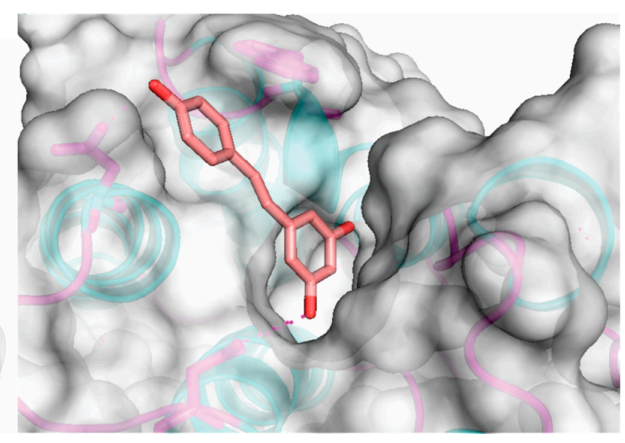

Figure 2. Molecular docking of BRD4(1) and RSV. A, hydrogens bond formed with Asn140 in the Kac binding site from BC-loop and Asn145 from $\alpha$ C. B, RSV interactions into Kac binding site and open ZA-loop pockets in surface mode. W81: Tryptofan 81; Y97: Tyrosine 97; N140: Asparagin 140; N145: Asparagine 145. 


\section{Discussion}

Modification upon chromatin structure such as methylation, acetylation, and phosphorylation have been broadly exploited as key point of understanding epigenetic mechanisms [20]. Lysine acetylation upon histone tails made by histone-acetyl transferases (HAT) drives to better accessibility of transcriptionally active genes to chromatin structure [21]. BET-BRDs recognize histone acetylation ("readers") and regulate gene expression involved in many diseases as cancers, inflammation, neurological disorders, and cardiovascular [20].

In this work, we demonstrated the capacity of resveratrol to interact with BET-BRDs using biophysical methods besides suggesting its binding mode into Kac of BRD4(1) through molecular docking studies. Therefore, we performed screening of RSV against BET-BRDs (BRD2, BRD3, BRD4, and BRDT) by setting DSF and ITC experiments. RSV showed thermal shift value for all BET-BRDs which ranged from 1.5 to $3.0^{\circ} \mathrm{C}$. ITC experiments confirmed the ability of RSV $\left(K_{d}=6.6 \mu \mathrm{M}\right)$ to interact with BRD4(1). The molecular docking study allows for the proposing of the mode of interaction of RSV with BRD4(1). Our data showed that RSV has a similar binding mode into Kac of BRD4(1) compared to other BRDs-inhibitors, which mimics polar interaction of acetyl-lysine with Asn140 into Kac [11,12]. Unlike others BRDs-inhibitors, RSV lacks hydrophobic interaction due to $\Delta S>0$ value. Hydrophobic interactions such as $\pi$-stacking with Trp81 into ZA-loop region appear to provide a higher affinity of inhibitors for BRD4(1) $[18,19]$.

BRD4 has been reported as target in various cancer types as ovarian, breast, gastric, andregulation of transcriptions factor MYC [6]. Interestingly, several BET inhibitors are on clinical trials targeting many cancer types, including the compounds OTX015 and GSK525762 for NUT midline carcinoma, acute myeloid leukemia and myelodysplastic syndrome (NCT02308761), and lymphoma (NCT01949883) and multiple myeloma (NCT02157636) [22]. Besides the activation of SIRT-1, which leads to deacetylation of transcription factors [23], RSV could present additional anticancer effect through BRD4 inhibition. SIRT-1 activation was demonstrated to suppress mammalian target of rapamycin (mTOR) in HeLa cells (Henrietta Lacks cells). This effect drives to autophagy activation and inhibition of cancer cells proliferation [24]. SIRT-1 also increases deacetylation on histone in the autophagy promoter region, promoting the dissociation of BRD4 from gene promoters [25].

Herein, we hypothesized that the anticancer effects of RSV could be related to dual activity, including SIRT-1 activation and BRDs inhibition [25]. However, further studies are required in order to elucidate the relation between this dual activity and autophagy mechanism.

\section{Conclusions}

Resveratrol was described for the first time to interact with BET-BRDs, being classified as a pan-BET inhibitor. This interesting effect can contribute to and explain the chemopreventive and anticancer effect of this polyphenol.

Acknowledgments: The authors thank the Programa de Apoio ao Desenvolvimento Científico da Faculdade de Ciências Farmacêutica da UNESP (PADC-FCF UNESP), Fundação de Amparo à Pesquisa do Estado de São Paulo (Fapesp; Process number2016/08880-8; 2015/19531-1; 2015/21271-9 and 2014/03945-9), and Conselho Nacional de Desenvolvimento Científico e Tecnológico (CNPq; Process: 310140/2014-5 and 200698/2014-1).

Author Contributions: All authors were involved in the concept and design of the study. L.A.D. and D.H. performed the DFS (Dynamic force spectroscopy) and ITC experiments; G.D.B.S. performed the docking experiment. S.K., J.L.S. and C.M.C. supervised this project. All authors were involved in the acquisition and/or interpretation of the data, made critical revisions to the manuscript for important intellectual content, and provided final approval of the version to be published.

Conflicts of Interest: The authors declare no conflict of interest. 


\section{References}

1. Dutra, L.A.; Guanaes, J.F.O.; Johmann, N.; Lopes Pires, M.E.; Chin, C.M.; Marcondes, S.; Dos Santos, J.L. Synthesis, antiplatelet and antithrombotic activities of resveratrol derivatives with NO-donor properties. Bioorg. Med. Chem. Lett. 2017, 27, 2450-2453. [CrossRef] [PubMed]

2. Ferraz da Costa, D.; Fialho, E.; Silva, J. Cancer Chemoprevention by Resveratrol: The p53 Tumor Suppressor Protein as a Promising Molecular Target. Molecules 2017, 22, 1014. [CrossRef] [PubMed]

3. Kimura, Y.; Sumiyoshi, M. Resveratrol Prevents Tumor Growth and Metastasis by Inhibiting Lymphangiogenesis and M2 Macrophage Activation and Differentiation in Tumor-associated Macrophages. Nutr. Cancer 2016, 68, 667-678. [CrossRef] [PubMed]

4. Yeh, C.B.; Hsieh, M.J.; Lin, C.W.; Chiou, H.L.; Lin, P.Y.; Chen, T.Y.; Yang, S.F. The Antimetastatic Effects of Resveratrol on Hepatocellular Carcinoma through the Downregulation of a Metastasis-Associated Protease by SP-1 Modulation. PLoS ONE 2013, 8. [CrossRef] [PubMed]

5. Lin, H.Y.; Tang, H.Y.; Davis, F.B.; Davis, P.J. Resveratrol and apoptosis. Ann. N. Y. Acad. Sci. 2011, 1215, 79-88. [CrossRef] [PubMed]

6. Guardi, M.; Frazzi, R. Cellular and Molecular Targets of Resveratrol on Lymphoma and Leukemia Cells. Molecules 2017, 22, 885. [CrossRef]

7. Feinberg, A.P.; Koldobskiy, M.A.; Göndör, A. Epigenetic modulators, modifiers and mediators in cancer aetiology and progression. Nat. Rev. Genet. 2016, 17, 284-299. [CrossRef] [PubMed]

8. Pavan, A.R.; da Silva, G.D.B.; Jornada, D.H.; Chiba, D.E.; Dos Santos Fernandes, G.F.; Chin, C.M.; dos Santos, J.L. Unraveling the anticancer effect of curcumin and resveratrol. Nutrients 2016, 8. [CrossRef] [PubMed]

9. Venturelli, S.; Berger, A.; Böcker, A.; Busch, C.; Weiland, T.; Noor, S.; Leischner, C.; Schleicher, S.; Mayer, M.; Weiss, T.S.; et al. Resveratrol as a Pan-HDAC Inhibitor Alters the Acetylation Status of Jistone Proteins in Human-Derived Hepatoblastoma Cells. PLoS ONE 2013, 8, 1-12. [CrossRef]

10. Filippakopoulos, P.; Knapp, S. Targeting bromodomains: epigenetic readers of lysine acetylation. Nat. Publ. Gr. 2014, 13, 337-356. [CrossRef] [PubMed]

11. Filippakopoulos, P.; Qi, J.; Picaud, S.; Shen, Y.; Smith, W.B.; Fedorov, O.; Morse, E.M.; Keates, T.; Hickman, T.T.; Felletar, I.; et al. Selective inhibition of BET bromodomains. Nature 2010, 468, 1067-1073. [CrossRef] [PubMed]

12. Picaud, S.; Wells, C.; Felletar, I.; Brotherton, D.; Martin, S.; Savitsky, P. RVX-208, an inhibitor of BET transcriptional regulators with selectivity for the second bromodomain. Proc. Natl. Acad. Sci. USA 2013, 110, 19754-19759. [CrossRef] [PubMed]

13. Laemmli, U.K. Cleavage of Structural Proteins during the Assembly of the Head of Bacteriophage T4. Nature 1970, 227, 680-685. [CrossRef] [PubMed]

14. Friesner, R.A.; Banks, J.L.; Murphy, R.B.; Halgren, T.A.; Klicic, J.J.; Mainz, D.T.; Repasky, M.P.; Knoll, E.H.; Shelley, M.; Perry, J.K.; et al. Glide: A New Approach for Rapid, Accurate Docking and Scoring. 1. Method and Assessment of Docking Accuracy. J. Med. Chem. 2004, 47, 1739-1749. [CrossRef] [PubMed]

15. Shelley, J.C.; Cholleti, A.; Frye, L.L.; Greenwood, J.R.; Timlin, M.R.; Uchimaya, M. Epik: A software program for $\mathrm{pKa}$ prediction and protonation state generation for drug-like molecules. J. Comput. Aided. Mol. Des. 2007, 21, 681-691. [CrossRef] [PubMed]

16. Liu, Z.; Wang, P.; Chen, H.; Wold, E.A.; Tian, B.; Brasier, A.R.; Zhou, J. Drug Discovery Targeting Bromodomain-Containing Protein 4. J. Med. Chem. 2017, 60, 4533-4558. [CrossRef] [PubMed]

17. Bromodomain, C.F.; Chaikuad, A.; Brennan, P.E.; Temperini, C.; Fedorov, O.; Hollander, J.; Nachane, R.; Abell, C.; Mu, S.; Siegal, G.; et al. Structure-Based Identi fi cation of Inhibitory Fragments Targeting the p300/CBP-Associated Factor Bromodomain. J. Med. Chem. 2016, 59, 1648-1653. [CrossRef]

18. Hewings, D.S.; Wang, M.; Philpott, M.; Fedorov, O.; Uttarkar, S.; Filippakopoulos, P.; Picaud, S.; Vuppusetty, C.; Marsden, B.; Knapp, S.; et al. 5-Dimethylisoxazoles Act As Acetyl-lysine-mimetic Bromodomain Ligands. J. Med. Chem. 2011, 54, 6761-6770. [CrossRef] [PubMed]

19. Hewitt, M.C.; Leblanc, Y.; Gehling, V.S.; Vaswani, R.G.; Nasveschuk, C.G.; Taylor, A.M.; Harmange, J.C.; Audia, J.E.; Pardo, E.; Cummings, R.; et al. Development of methyl isoxazoleazepines as inhibitors of BET. Bioorg. Med. Chem. Lett. 2015, 25, 1842-1848. [CrossRef] [PubMed] 
20. Brand, M.; Measures, A.M.; Wilson, B.G.; Cortopassi, W.A.; Alexander, R.; Ho, M.; Hewings, D.S.; Rooney, T.P.C.; Paton, R.S.; Conway, S.J. Small Molecule Inhibitors of Bromodomain-Acetyl-lysine Interactions. ACS Chem. Biol. 2015, 10, 22-39. [CrossRef] [PubMed]

21. Conway, S.J. Bromodomains: Are Readers Right for Epigenetic Therapy? ACS Med. Chem. Lett. 2012, 3, 691-694.

22. Andrieu, G.; Belkina, A.C.; Denis, G.V. Clinical trials for BET inhibitors run ahead of the science. Drug Discov. Today Technol. 2016, 19, 45-50. [CrossRef] [PubMed]

23. Park, D.; Jeong, H.; Lee, M.N.; Koh, A.; Kwon, O.; Yang, Y.R.; Noh, J.; Suh, P.-G.; Park, H.; Ryu, S.H. Resveratrol induces autophagy by directly inhibiting mTOR through ATP competition. Sci. Rep. 2016, 6, 21772. [CrossRef] [PubMed]

24. Ghosh, H.S.; McBurney, M.; Robbins, P.D. SIRT1 negatively regulates the mammalian target of rapamycin. PLoS ONE 2010, 5, e9199. [CrossRef] [PubMed]

25. Sakamaki, J.; Wilkinson, S.; Hahn, M.; Tasdemir, N.; O’Prey, J.; Clark, W.; Hedley, A.; Nixon, C.; Long, J.S.; New, M.; et al. Bromodomain Protein BRD4 Is a Transcriptional Repressor of Autophagy and Lysosomal Function. Mol. Cell 2017, 66, 517-532.e9. [CrossRef] [PubMed]

(C) 2017 by the authors. Licensee MDPI, Basel, Switzerland. This article is an open access article distributed under the terms and conditions of the Creative Commons Attribution (CC BY) license (http:/ / creativecommons.org/licenses/by/4.0/). 